\title{
Article
}

\section{Families may benefit from spiritual care in acute settings when loved ones are coming to the end of their lives}

Boland, Paul, Geddes, Zoe and Hill, James Edward

Available at https://clok.uclan.ac.uk/34633/

Boland, Paul orcid iconORCID: 0000-0003-2267-4295, Geddes, Zoe and Hill, James Edward orcid iconORCID: 0000-0003-1430-6927 (2020) Families may benefit from spiritual care in acute settings when loved ones are coming to the end of their lives. Evidence Based Nursing . ISSN 1367-6539

It is advisable to refer to the publisher's version if you intend to cite from the work. http://dx.doi.org/10.1136/ebnurs-2020-103279

For more information about UCLan's research in this area go to http://www.uclan.ac.uk/researchgroups/ and search for <name of research Group>.

For information about Research generally at UCLan please go to http://www.uclan.ac.uk/research/

All outputs in CLoK are protected by Intellectual Property Rights law, including Copyright law. Copyright, IPR and Moral Rights for the works on this site are retained by the individual authors and/or other copyright owners. Terms and conditions for use of this material are defined in the policies page.

\section{CLoK}

Central Lancashire online Knowledge www.clok.uclan.ac.uk

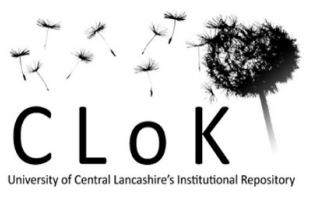


Author's declarative title: Families may benefit from spiritual care in acute settings when loved ones are coming to the end of their lives.

Commentary on: Hennessy N, Neenan K, Brady V, Sullivan M, Eustace-Cooke J, Timmins $\mathrm{F}$. End of life in acute hospital setting-A systematic review of families' experience of spiritual care. Journal of Clinical Nursing. 2020;29(7-8):1041-52.

\section{Commentary}

Implications for practice and research

- Nurses are ideally placed to provide spiritual care within the acute hospital setting.

- Communication, collaboration, and facilitation are essential when providing good spiritual care.

- Future research should focus on barriers and facilitators of spiritual care within the acute hospital setting.

\section{Context}

Over half of the deaths in the United Kingdom occur in acute hospital settings (1). However, compared to palliative care in hospices and palliative care settings, the evidence for end of life care in the acute hospital setting is less consistent and developed (2), with the majority of this research focusing on the experiences of patients and healthcare providers (3) rather than from a families' perspective. Therefore, this review seeks to examine families' experiences of spiritual care at the end of life in the acute hospital setting (3).

\section{Methods}

This qualitative systematic review undertook a comprehensive multi-database search. Only studies in English and Spanish were included that focused on the spiritual care experiences of families with adult relatives receiving end of life care, within a hospital setting. Screening, data extraction and quality assessment (an adapted version of the COREQ 32-item checklist) were carried out by a team of three authors, two working as a pair and one author acting as verification. A thematic analysis was performed on the data by a single reviewer.

\section{Findings}

From the nine included studies, five core themes emerged. Firstly, anticipating needs was important, with families needing spiritual support, clear communication, and the need to spend time with loved ones with appropriate comfort. Secondly, families appreciated it when they were included in undertaking the care for their loved one and that they witnessed that their relative was treated with dignity and respect. Thirdly, healthcare providers showing empathy and having a personal connection with their loved one was 
valued. Fourthly, some family members reported that they had experienced a lack of sensitivity by some healthcare professionals. Finally, making space for spiritual and religious practices by providing appropriate items, facilitating rituals, and having pastoral care workers' support was found to be comforting.

\section{Commentary}

Using the Joanna Briggs Institute of Critical Appraisal tool for systematic reviews nine out of the eleven criteria were judged to be satisfactory for this review. Thus, it was deemed that this systematic review might provide a comprehensive summary of the available studies that address the question of interest. However, it is important to note that there was no date given for last search and no indication that data saturation was met (4). Therefore, it is difficult to identify how comprehensive/up to date these findings are.

This review highlights how nurses are ideally placed to anticipate and facilitate the families' needs. In particular to ensure that there is clear communication and the families' spiritual and comfort needs are appropriately being met, as spiritual conversations can help improve the patient's satisfaction and patient and family well-being (5). This can be in ensuring that appropriate space and appropriate items are provided and that access to pastoral care workers/faith leaders are made available. Previous evidence has suggested that pastoral care workers/faith leaders should be seen as a vital member of the palliative care team and if possible, should be available on call (5).

When carrying out end of life care, nurses should enquire whether families want to assist with care/end of life rituals of their family member. This collaboration could facilitate in families observing a healthcare professionals' personal connection with their patients. It is also important that these strategies are dynamic and can be adapted for each individual and should be used with a patient centred approach.

This review also highlighted some possible barriers to appropriate spiritual care at the end of life in acute hospital settings, such as the demands of the service, a perceived lack of communication and sensitivity, and possible delays in receiving spiritual support which can increase family stress and suffering. Further research through observational studies could look to explore these barriers further and identify additional facilitators which could improve the experiences of families and patients.

\section{References}

1. Ziwary SR, Samad D, Johnson CD, Edwards RT. Impact of place of residence on place of death in Wales: an observational study. BMC Palliative Care. 2017;16(1):72.

2. Irish Hospice Foundation. Our impact 1996-2016. Dublin, Ireland: Irish Hospice Foundation.; 2016.

3. Hennessy N, Neenan K, Brady V, Sullivan M, Eustace-Cooke J, Timmins F. End of life in acute hospital setting - A systematic review of families' experience of spiritual care. Journal of Clinical Nursing. 2020;29(7-8):1041-52.

4. Saunders, B., Sim, J., Kingstone, T., Baker, S., Waterfield, J., Bartlam, B., Burroughs, H., \& Jinks, C. Saturation in qualitative research: exploring its conceptualization and operationalization. Quality \& quantity, 2018;52(4), 1893-1907.

https://doi.org/10.1007/s11135-017-0574-8 
5. Gijsberts, M., Liefbroer, A. I., Otten, R., \& Olsman, E. Spiritual Care in Palliative Care: A Systematic Review of the Recent European Literature. Medical sciences (Basel,

Switzerland), 2019;7(2), 25. https://doi.org/10.3390/medsci7020025

\section{Commentator details}

Name: James Edward Hill

Affiliation: University of Central Lancashire

Correspondence address:

University of Central Lancashire,

Preston,

Lancashire

PR1 2HE

Email: Jehill1@uclan.ac.uk

\section{Competing interests}

I have no conflicts of interest with any aspect of this publication.

Acknowledgements: This report is independent research funded by the National Institute for Health Research Applied Research Collaboration North West Coast (ARC NWC). The views expressed in this publication are those of the author(s) and not necessarily those of the National Institute for Health Research or the Department of Health and Social Care. 